\title{
Elevated red blood cell distribution width as a marker of higher risk for contrast-induced nephropathy: A systematic review and meta-analysis
}

\author{
Wenbo Zhao', Zifeng Liu ${ }^{2}$, Tohty Rahman ${ }^{3}$, Yanru Chen ${ }^{1}$, De La Pena Serna Mario Alberto ${ }^{3}$, Yashi \\ Zhan $^{4}$, Hui Peng ${ }^{1 \#}$, Xun Liü ${ }^{1, \#}$ \\ ${ }^{1}$ Department of Nephrology, The Third Affiliated Hospital of Sun Yat-sen University, Guangzhou, 510632, China; \\ ${ }^{2}$ Department of Clinical Data Center, The Third Affiliated Hospital of Sun Yat-sen University, 510632, Guangzhou, \\ China; ${ }^{3}$ Zhongshan School of Medicine, Sun Yat-sen University, Guangzhou, 510630, China; ${ }^{4}$ Kangyacare, \\ incorporated, California, 92602, USA
}

*Corresponding authors: Dr. Xun Liu, Department of Nephrology, The Third Affiliated Hospital of Sun Yat-sen University, Tianhe Road No. 600, Guangzhou 510632, China E-mail: bobo800101@ foxmail.com

"These authors contributed equally to this work.

Received October 28, 2019; Accepted December 17, 2019

\begin{abstract}
Background and objectives: Contrast-induced nephropathy (CIN) after the use of contrast media in patients is a common complication associated with a poorer outcome. The large sample research of the correlation between RDW and CIN is lack. We performed a meta-analysis and systematic review to investigate the value of red cell distribution width (RDW) as a marker in the early prediction of CIN. Methods: Relevant articles were selected from the databases of PubMed, EMBASE and the Cochrane Library until May 28, 2018, to identify eligible cohort and case-control studies evaluating RDW levels to predict CIN. Overall odds ratio (OR) of the effect of RDW for CIN were pooled and shown in forest plots. Results: Seven studies with a total of 3,048 patients were included in this meta-analysis. The combined results based on the pooling of the 7 studies that provided related data indicated that the elevated RDW was related to CIN (OR, 1.35 (95\% CI, 1.11-1.65)). Furthermore, similar results were in-analysis stratified by acute coronary syndrome (ACS), ST-segment elevation myocardial infarction (STEMI) and/or non-ST-segment elevation myocardial infarction (NSTEMI) $(0 R, 1.45$ (95\% CI, 1.29-1.64)) and ACS only STEMI(OR, 1.58 (95\% CI, 1.35-1.85)). For every $1 \%$ increase in RDW, the risk of CIN was increased by $45 \%$ in ACS patients and increased by $58 \%$ in STEMI patients. Conclusions: This meta-analysis demonstrated that RDW could be a potential risk factor in CIN patients, and that higher RDW may have higher risk than those with lower RDW in ACS, especially in STEMI patients.
\end{abstract}

Key Words: red blood cell distribution width; contrast-induced nephropathy; acute coronary syndrome; ST-segment elevation myocardial infarction; meta-analysis

\section{INTRODUCTION}

The use of contrast media in medical practice has been rapidly increasing in radiologic imaging and interventional therapy. Some patients developed contrast-induced nephropathy (CIN) after undergoing these diagnostic and therapeutic procedures. ${ }^{1}$ The development of CIN is associated with poor clinical outcomes including prolonged hospitalization and increased cost, risk of end-stage renal failure, and mortality. ${ }^{2-4} \mathrm{~A} 3$-fold higher risk of CIN was developed in acute coronary syndrome (ACS). ${ }^{5-7}$ The poor outcome is caused partly by the lack of a predictive marker for CIN. Therefore, strategies for predicting CIN and its prevention are important.

Erythrocyte variability and heterogeneity are measured by red cell distribution width (RDW), which is obtained by the standard complete blood cell counts. ${ }^{8,9}$ Increased RDW indicates un-

This is an open access journal, and articles are distributed under the terms of the Creative Commons Attribution-NonCommercial-ShareAlike 4.0 License, which allows others to remix, tweak, and build upon the work non-commercially, as long as appropriate credit is given and the new creations are licensed under the identical terms.

For reprints contact: weda-h@ weda-h.org

How to cite this article: Zhao WB, Liu ZF, Rahman T, Chen YR, De La Pena S, Peng H, Liu X. Elevated red blood cell distribution width as a marker of higher risk for contrast-induced nephropathy: A systematic review and meta-analysis. $J A D V$ HEALTH 2019; 1(4): 239-244. 
uniform size, which is related to them echanism of erythropoiesis obstacle and red cell degradation. Increased RDW reflects chronic inflammation and oxidative stress. ${ }^{10,11} \mathrm{RDW}$ was related with high-sensitivity Creactive protein (hsCRP), and erythrocyte sedimentation rate (ESR). However, S. Bello et al. found no association between inflammatory markers (CRP, PCT and WBC) and long-term community-acquired pneumonia mortality. Studies have shown that an increased RDW is associated with poor clinical cardiac outcomes in various clinical settings, included patients with heart failure, ${ }^{12-14}$ slow coronary blood flow, ${ }^{15}$ stable coronary artery disease, ${ }^{16,17} \mathrm{ACS},{ }^{18-21}$ and those undergoing percutaneous coronary intervention (PCI). ${ }^{22}$ Due to the potential mechanism of inflammation and oxidative stress in the development of CIN, RDW might be a marker of CIN risk. However, whether RDW is related to CIN risk remains unclear. The large sample research of the correlation between RDW and CIN is lacking. To date, no independent meta-analysis has been carried out to identify. Thus, we performed a systemic review and meta-analysis to investigate whether elevated RDW levels are associated with the development of CIN, especially PCI in patients with ACS.

\section{MATERIALS AND METOODS}

\section{Search Strategy}

The Preferred Reporting Items for Systematic Reviews and Meta-analyses (PRISMA) guidelines were applied in this systemic review and meta-analysis. The databases used in the search for pertinent articles included PubMed, EMBASE, and the Cochrane Library to identify eligible studies published up to May 28, 2018. The search terms for all three databases were "erythrocyte indices", "red blood cell distribution width", "RDW", "contrast-induced nephropathy", "CIN", and "radiographic contrast nephropathy". Manual retrievals were also performed by reviewing the references of the eligible studies. One reviewer performed the retrieval, whereas another confirmed the process.

\section{Study Selection}

By using titles, abstracts, and/or full articles, the search yielded 7 articles. The inclusion criterion included studies investigating the RDW values for CIN risk [studies including the odds ratio (OR)]. The outcomes of the studies were reported in terms of the CIN rate. The full text was considered in terms of its eligibility for inclusion. The criteria for exclusion included patients lacking laboratory RDW data, studies without OR, animal studies, abstracts, duplicated publications, or those published in languages other than English. While screening the citations, two reviewers independently reviewed the search results to determine article inclusion. In cases of discord, a consensus was reached through discussion with the articles' authors.

\section{Data Extraction and Quality Assessment}

Data extraction and quality assessment were performed independently by two authors. The following data were extracted from eligible studies using standardized forms by documenting or recalculating the following variables: names of the first authors, sources of patients, publication year, sample sizes, characteristics of patients, event rates, the corresponding OR and 95\% confidence intervals (CIs), CIN definition, timing of RDW measurement, and the confounding factors adjusted for. The Newcastle-Ottawa Scale (NOS) was used to assess the quality of the included studies.

\section{Statistical Analysis}

This meta-analysis was performed and reported in accordance with the PRISMA guidelines for systematic reviews and meta-analyses. ${ }^{23}$ The systematic review with assessed RDW value was related to CIN risk in people. Meanwhile, subgroup analysis was performed to explore the possible source of heterogeneity. For comparison of different populations of RDW value related to the incidence of CIN, the population of ACS was divided into groups of ACS patients with both ST-segment elevation myocardial infarction (STEMI) and non-ST-segment elevation myocardial infarction (NSTEMI), and ACS patients with STEMI only. For the heterogeneity assessment, we used Cochrane's Q test (significance level of $P<0.10$ ), as well as the $I^{2}$ statistics in the eligible studies. If $I^{2}>50 \%$ or $P<0.10$, the OR were pooled using a random-effects model; otherwise, the OR were pooled using a fixed-effects model. Sensitivity analysis was conducted to exclude any single study that may have resulted in a significant change to the final results. Funnel plots was applied to evaluate the potential publication bias. ${ }^{23}$ All analyses were performed using R software.

\section{RESULTS}

The search yielded 9 articles that were assessed using titles, abstracts, and/or full articles, and 9 reviewed full-text articles, of which 2 articles were excluded for the reasons shown in Figure 1. Seven studies with a total of 3,048 patients were included for this meta-analysis. [Figure 1, Table 1]

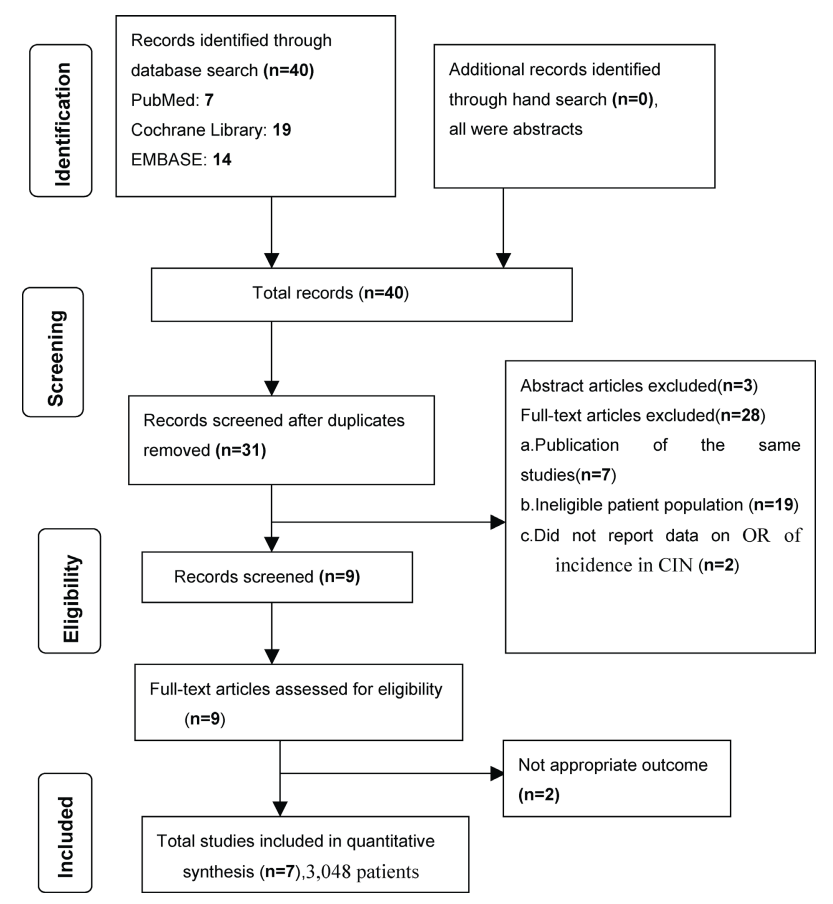

Figure 1 Study flow diagram

\section{Summary of the Eligible Studies}

As the flowchart in Figure 1 shows, a total of 7 studies $^{24-30}$ meeting 
Table 1 The characteristics of included studies

\begin{tabular}{|c|c|c|c|c|c|c|c|c|}
\hline First Author(year) & Country & Study population & Sample size & Study design & OR & Selection & Comparability & Outcome \\
\hline Atsushi Mizuno $(2015)^{24}$ & Japan & $\begin{array}{c}\text { STEMI patients without } \\
\text { hemodialysis }\end{array}$ & 102 & cohort study & $2.029(1.029-3.999)$ & $\star \star \star \star \star$ & $\star \star$ & $\star \star \star$ \\
\hline Ertan Vurus, kan $(2017)^{25}$ & Turkey & $\begin{array}{l}\text { Patients with peripheral } \\
\text { artery disease }\end{array}$ & 359 & case-control study & $0.943(0.822-1.055)$ & $\star \star \star$ & $\star \star$ & $\star \star \star$ \\
\hline $\begin{array}{c}\text { Katarzyna Zbierska } \\
\text {-Rubinkiewicz }(2017)^{26}\end{array}$ & Poland & $\begin{array}{l}\text { NSTEMI and STEMI } \\
\text { patients }\end{array}$ & 257 & cohort study & $1.30[1.04-1.61]$ & $\star \star \star \star \star$ & $\star \star$ & $\star \star \star$ \\
\hline Alparslan Kurtul $(2015)^{27}$ & Turkey & $\begin{array}{c}\text { ACS (STEMI, NSTEMI) } \\
\text { who underwent PCI }\end{array}$ & 662 & cohort study & $1.379(1.084-1.753)$ & $\star \star \star \star \star$ & $\star \star$ & $\star \star \star$ \\
\hline Fatih Akin $(2015)^{28}$ & Turkey & STEMI & 630 & cohort study & $1.406(1.120-1.792)$ & $\star \star \star \star \star$ & $\star \star$ & $\star \star \star$ \\
\hline $\begin{array}{l}\text { Dursun Çayan Akkoyun } \\
(2015)^{29}\end{array}$ & Turkey & STEMI & 359 & cohort study & $1.716(1.363-2.157)$ & $\star \star \star \star$ & $\star \star$ & $\star \star \star$ \\
\hline Kai Zhao $(2015)^{30}$ & China & $\begin{array}{l}\text { SAP patients who } \\
\text { underwent PCI }\end{array}$ & 679 & cohort study & $1.381(1.086-1.757)$ & $\star \star \star \star \star ~$ & $\star \star$ & $\star \star \star$ \\
\hline
\end{tabular}

our included criteria were initially collected through our search strategy. Overall, 6 cohort studies ${ }^{24,26-30}$ and 1 case-control study, ${ }^{25}$ with a total of 3,048 CIN patients, were included in our meta-analysis. Six articles ${ }^{24,26-30}$ were prospective cohort studies, whereas one ${ }^{25}$ was a retrospective study. Five studies ${ }^{24,26-29}$ included patients who accepted PCI therapy because of ACS (including STEMI or NSTEMI), one study ${ }^{25}$ involved stable angina pectoris (SAP) patients, and one study ${ }^{30}$ addressed patients with peripheral artery disease. The characteristics' summary of the eligible studies is given in Table 1.

For quality assessment, one of the studies was considered as having mild cohort selection bias because it was designed as a retrospective study. ${ }^{25}$

\section{Main Findings of the Eligible Studies}

We summarized the data from the 7 eligible articles and analyzed them by the forest figure [Figure 2]. The OR values in 6 studies were more than 1.0, indicating that wide RDW is a risk factor of CIN in patients who accepted PCI therapy because of ACS (including STEMI or NSTEMI) and SAP, while only one study of patients with peripheral artery disease showed that elevated RDW had low risk $(\mathrm{OR}=0.943,95 \% \mathrm{CI}, 0.822-1.055)$. Among the 6 studies, the maximum OR value was $2.03(95 \% \mathrm{CI}, 1.03-4.0)$, while the minimum was 1.30 (95\% CI, 1.04-1.62). Meanwhile, when we studied the random effect model for all 7 studies, the OR value was 1.35 (95\% CI, 1.09-1.76)[Figure 2].

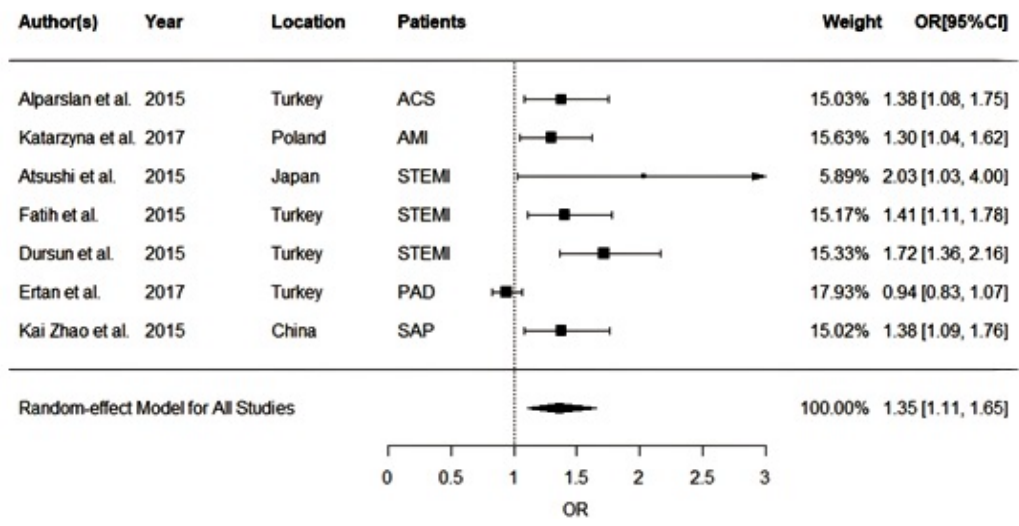

Figure 2 The pooled CIN risk demonstrated by forest plot.

Interestingly, however, we found that the OR value in STEMI patients was higher than that of the ACS (Studies including STEMI and/or NSTEMI) or SAP group. As a consequence, we divided the studies into two subgroups of the ACS (STEMI and/or NSTEMI) subgroup and the STEMI subgroup to explore the possible heterogeneity.

\section{Subgroup Analysis}

As referred above, we performed subgroup analysis to explore the possible heterogeneity. We also performed a forest plot (Figure 3) to allow further analysis. The summarized OR values in both ACS
(STEMI and/or NSTEMI) and STEMI subgroups were significantly higher, and the OR value in the STEMI subgroup (OR 1.58, 95\% CI, 1.35-1.85) was higher than that of the ACS subgroup (OR 1.45, 95\% CI, 1.29-1.64).

\section{Publication Bias}

Publication bias was described by a funnel plot [Figure 4] for the 7 studies included in the meta-analysis and asymmetry was observed, and indicated that there is no significant publishing bias across the eligible studies. 


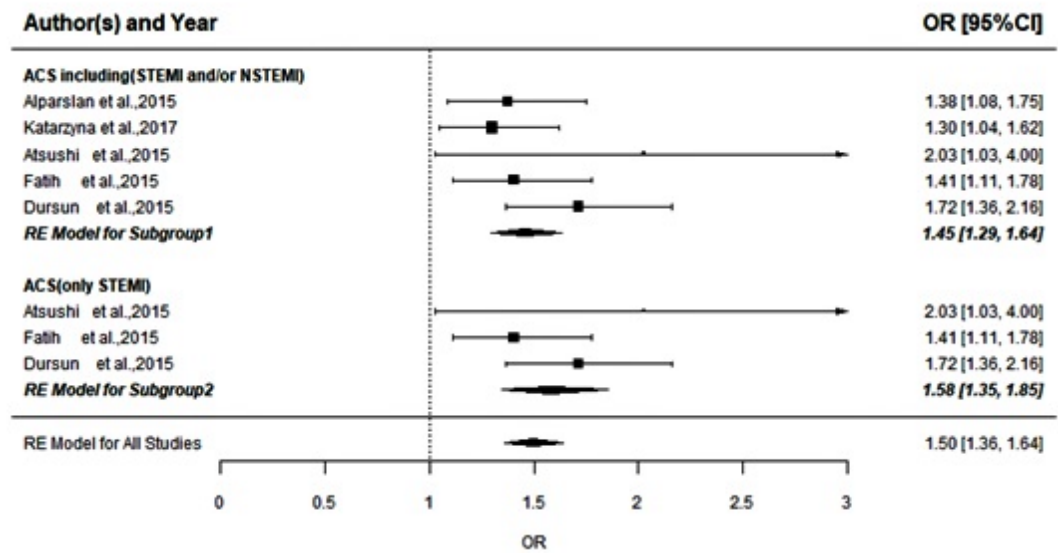

Figure 3 The pooled CIN risk (ACS, STEMI, and NSTEMI) and the pooled CIN risk (STEMI) demonstrated by forest plots.

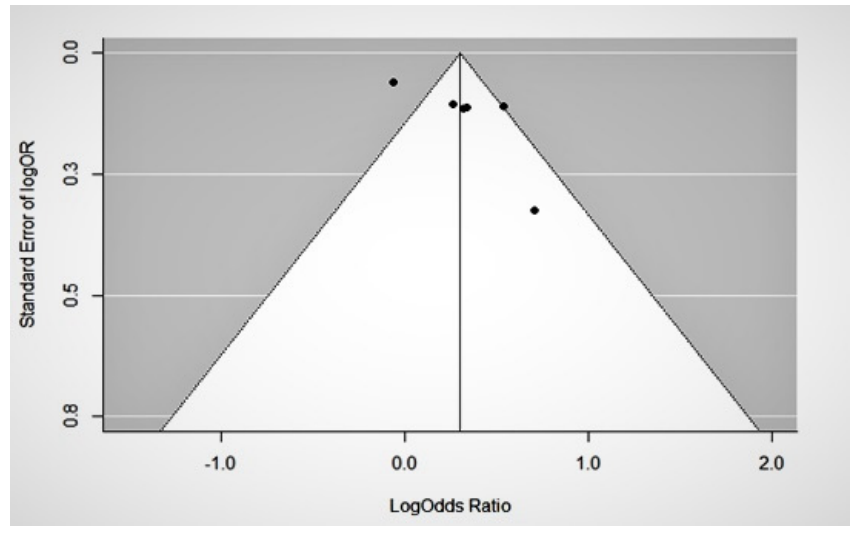

Figure 4 Funnel plot representing 7 studies.

\section{Sensitivity Analysis}

We conducted sensitivity analysis to determine whether to exclude any single study, where the leave one out function was used. It was found that no single study required exclusion.

\section{DISCUSSION}

The present systematic review and meta-analysis indicated that increased RDW was significantly associated with increased risk of CIN in patients who had used contrast media. RDW is heterogeneity of erythrocyte measurement. Increased RDW reflected chronic inflammation and oxidative stress, ${ }^{10,11,31}$ relating to impaired erythropoiesis and erythrocyte degradation.

Although the pathogenesis of CIN is not completely clear, a variety of mechanisms have been found, with inflammation playing an important role. Elevated C-reactive protein, erythrocyte sedimentation rate, and pro-inflammatory cytokines were associated with elevated RDW, and an increased risk of CIN. ${ }^{32,33}$ The statin treatment for CIN and renal protection link with anti-inflammatory activity. ${ }^{34,35}$ Inflammation may influence red blood cell maturation to elevate RDW, ${ }^{36}$ where the increased RDW levels may be associated with oxidative stress, caused by the release of reactive oxygen species (ROS) $)^{37}$ and CIN. Two studies demonstrated that reducing the production of ROS could lower the risk of CIN. ${ }^{38,39}$ Oxidative stress leads to shortened red cell survival and increase RDW. Consequently, elevated RDW levels may reflect an elevated inflammatory response and a high risk of developing
CIN.

RDW at the baseline is associated with higher CIN in patients using contrast media. The results of the 7 studies included in the meta-analysis demonstrated that the pooled OR for CIN was 1.35, which suggests that elevated RDW is associated with higher CIN risk. For every $1 \%$ increase in RDW, the risk of CIN in ACS patients was increased by $35 \%$. Meanwhile, only one study of patients with peripheral artery disease showed elevated RDW had a low risk (OR 0.943). Since there was fewer studies focused on CIN due to peripheral artery disease, further research should be conducted. Therefore, we performed subgroup analysis. Similar results were achieved in the analysis stratified by ACS (STEMI and/or NSTEMI) [1.45 (95\% CI, 1.29-1.64)] and ACS but only STEMI [1.58 (95\% CI, 1.35-1.85)]. Forevery 1\% increase in RDW, the risk of CIN in ACS patients was increased by $45 \%$ and the risk of CIN in STEMI patients was increased by $58 \%$.

The subgroup analyses suggest that the summarized OR value in the ACS (STEMI and/or NSTEMI) subgroup is higher (OR 1.45), meaning that for every $1 \%$ increase in RDW, the risk of CIN increased by $45 \%$ in the ACS patients. The summarized OR value in the STEMI subgroup (OR 1.58) was significantly higher than that of the ACS subgroup, indicating that for every $1 \%$ increase in RDW, the risk of CIN increased by $58 \%$ in the STEMI patients. The STEMI subgroup (OR 1.58) was higher than that of the ACS (STEMI and/or NSTEMI) subgroup (OR 1.45), suggesting that higher RDW may have a poorer prognosis in STEMI patients than in NSTEMI patients. But, since the subgroup analyses of NSTEMI patients did not identify sufficient data, further studies should be conducted.

Some limitations must be acknowledged in the present systematic review and meta-analysis. First, publication bias existed, that may be that only 7 studies were included in the final and the sample sizes were small. Further studies should be performed, with larger sample sizes and adjusted for confounding factors. Second, the individual studies had their different confounding factors adjusted, such as diabetic patients and nephropathy patients having a higher CIN incidence without subgroup analysis, which may have led to bias. Third, there was a relative paucity of studies on patients with peripheral artery disease and NSTEMI patients, which may have affected the results of the analysis. Lastly, this systematic reviews is not registered online, but our meta-analysis was conducted in strict process accordance with the Preferred Reporting Items for Systematic Reviews and Meta-analyses (PRISMA) guidelines, so the bias of our research tends to be less. 
In conclusion, the results of this systematic review and meta-analysis indicate that elevated RDW may be a risk factor for CIN, and higher RDW may have poorer prognosis than those with lower RDW in ACS, especially in STEMI patients. Further studies are needed to explore the potential mechanisms underlying this association.

\section{Disclosure Statement}

The authors report no conflict of interest.

\section{REFERENCES}

1. Parfrey P. The clinical epidemiology of contrast-induced nephropathy. Cardiovasc Intervent Radiol 2005; 28(Suppl 2): S3-11.

2. Recio-M ayorl A, Chaparro M, Prado B, Cózar R, Méndez I, Banerjee D, Kaski JC, Cubero J, Cruz JM.The reno-protective effect of hydration with sodium bicarbonate plus $\mathrm{N}$-acetylcysteine in patients undergoing emergency percutaneous coronary intervention: the RENO Study. J Am Coll Cardiol 2007; 49(12): 1283-8.

3. Lazaros G, Tsiachris D, Tousoulis D, Patialiakas A, Dimitriadis K, Roussos D, Vergopoulos E, Tsioufis C, Vlachopoulos C, Stefanadis C. In-hospital worsening renal function is an independent predictor of one-year mortality in patients with acute myocardial infarction. Int $J$ Cardiol 2012; 155(1): 97-101.

4. Bartholomew BA, Harjai KJ, Dukkipati S, Boura JA, Yerkey MW, Glazier S, Grines CL, O'Neill WW. Impact of nephropathy after percutaneous coronary intervention and a method for risk stratification. Am J Cardiol 2004; 93(12): 1515-9.

5. Mehran R, Aymong ED, Nikolsky E, Lasic Z, Iakovou I, Fahy M, Mintz GS, Lansky AJ, Moses JW, Stone GW, Leon MB, Dangas G. A simple risk score for prediction of contrast-induced nephropathy after percutaneous coronary intervention: development and initial validation. J Am Coll Cardiol 2004; 44(7): 1393-9.

6. Senoo T, Motohiro M, Kamihata H, Yamamoto S, Isono T, Manabe K, Sakuma T, Yoshida S, Sutani Y, Iwasaka T. Contrast-induced nephropathy in patients undergoing emergency percutaneous coronary intervention for acute coronary syndrome. Am J Cardiol 2010; 105(5): 624-8.

7. McCullough PA, Stacul F, Becker CR, Adam A, Lameire N, Tumlin JA, Davidson CJ. Contrast-Induced Nephropathy (CIN) Consensus Working Panel: executive summary. Rev Cardiovasc Med 2006; 7(4): 177-97.

8. Aung N, Ling HZ, Cheng AS, Flint J, Mendonca M, Rashid M, Kang S, Weissert S, Coats CJ, Richards T, Thomas M, Woldman S, Okonko DO. Expansion of the red cell distribution width and evolving iron deficiency as predictors of poor outcome in chronic heart failure. Int $J$ Cardiol 2013; 168(3): 1997-2002.

9. Lin CK, Lin JS, Chen SY, Jiang ML, Chiu CF. Comparison of hemoglobin and red blood cell distribution width in the differential diagnosis of microcytic anemia. Arch Pathol Lab Med 1992; 116(10): 1030-2.

10. Ferrucci L, Guralnik JM, Woodman RC, Bandinelli S, Lauretani F, Corsi AM, Chaves PH, Ershler WB, Longo DL. Proinflammatory state and circulating erythropoietin in persons with and without anemia. Am J Med 2005; 118(11): 1288.

11. Semba RD, Patel KV, Ferrucci L, Roy CN, Guralnik JM, Fried LP. Serum antioxidants and inflammation predict red cell distribution width in older women: the Women's Health and Aging Study I. Clin Nutr 2010; 29(5): 600-4.

12. Felker GM, Allen LA, Pocock SJ, Shaw LK, McMurray JJ, Pfeffer MA,
Swedberg K, Wang D, Yusuf S, Michelson EL, Granger CB. Red cell distribution width as a novel prognostic marker in heart failure: data from the CHARM Program and the Duke Databank. J Am Coll Cardiol 2007; 50(1): 40-7.

13. Pascual-Figal DA, Bonaque JC, Redondo B, Caro C, ManzanoFernandez S, Sánchez-Mas J, Garrido IP, Valdes M. Red blood cell distribution width predicts long-term outcome regardless of anaemia status in acute heart failure patients. Eur J Heart Fail 2009; 11(9): 840-6.

14. Núñez J, Núñez E, Rizopoulos D, Miñana G, Bodí V;Bondanza L, Husser O, Merlos P, Santas E, Pascual-Figal D, Chorro FJ, Sanchis J. Red blood cell distribution width is longitudinally associated with mortality and anemia in heart failure patients. Circ J 2014; 78(2): 410-8.

15. Kalay N, Aytekin M, Kaya MG, Ozbek K, Karayakalı M, Söğüt E, Altunkas F, Oztürk A, Koç F. The relationship between inflammation and slow coronary flow: increased red cell distribution width and serum uric acid levels. Turk Kardiyol Dern Ars 2011; 39(6): 463-8.

16. Tonelli M, Sacks F, Arnold M, Moye L, Davis B, Pfeffer M. Relation Between Red Blood Cell Distribution Width and Cardiovascular Event Rate in People With Coronary Disease. Circulation 2008; 117(2): 163-168.

17. Osadnik T, Strzelczyk J, Hawranek M, Lekston A, Wasilewski J, Kurek A, Gutowski AR, Wilczek K, Dyrbuś K, Gierlotka M, Wiczkowski A, Gąsior M, Szafranek A, Poloński L. Red cell distribution width is associated with long-term prognosis in patients with stable coronary artery disease. BMC Cardiovasc Disord 2013; 13: 113.

18. Nabais S, Losa N, Gaspar A, Rocha S, Costa J, Azevedo P, Basto L, Pereira MA, Correia A. Association between red blood cell distribution width and outcomes at six months in patients with acute coronary syndromes. Rev Port Cardiol 2009; 28(9): 905-24.

19. Lippi G, Filippozzi L, Montagnana M, Salvagno GL, Franchini M, Guidi GC, Targher G. Clinical usefulness of measuring red blood cell distribution width on admission in patients with acute coronary syndromes. Clin Chem Lab Med 2009; 47(3): 353-7.

20. Uyarel H, Ergelen M, Cicek G, Kaya MG, Ayhan E, Turkkan C, Yildırım E, Kırbas V, Onturk ET, Erer HB, Yesilcimen K, Gibson CM. Red cell distribution width as a novel prognostic marker in patients undergoing primary angioplasty for acute myocardial infarction. Coron Artery Dis 2011; 22(3): 138-44.

21. Dabbah S, Hammerman H, Markiewicz W, Aronson D. Relation between red cell distribution width and clinical outcomes after acute myocardial infarction. Am J Cardiol 2010; 105(3): 312-7.

22. Fatemi O, Paranilam J, Rainow A, Kennedy K, Choi J, Cutlip D, Pencina M, Berger PB, Cohen DJ, Kleiman NS. Red cell distribution width is a predictor of mortality in patients undergoing percutaneous coronary intervention. J Thromb Thrombolysis 2013; 35(1): 57-64.

23. Moher D, Liberati A, Tetzlaff J, Altman DG. Preferred reporting items for systematic reviews and meta-analyses: the PRISMA statement. Ann Intern Med 2009; 151(4): 264-9, W64.

24. Mizuno A, Ohde S, Nishizaki Y, Komatsu Y, Niwa K. Additional value of the red blood cell distribution width to the Mehran risk score for predicting contrast-induced acute kidney injury in patients with ST-elevation acute myocardial infarction. J Cardiol 2015; 66(1): 41-5.

25. Vuruşkan E, Saraçoğlu E. Bilirubin Levels are Associated With Contrast-Induced Nephropathy in Peripheral Artery Disease. Angiology 2017; 68(8): 728-733.

26. Zbierska-Rubinkiewicz K, Trębacz O, Tomala M, Rubinkiewicz M, Chrzan I, Gackowski A. Creatine kinase-MB and red cell distribution width as predictors of contrast-induced nephropathy after percutaneous coronary intervention in acute myocardial infarction. 
Folia Med Cracov 2017; 57(3): 87-99.

27. Kurtul A, Yarlioglues M, Murat SN, Demircelik MB, Acikgoz SK, Ergun G, Duran M, Cetin M, Ornek E. Red cell distribution width predicts contrast-induced nephropathy in patients undergoing percutaneous coronary intervention for acute coronary syndrome. Angiology 2015; 66(5): 433-40.

28. Akin F, Celik O, Altun I, Ayca B, Ozturk D, Satilmis S, Ayaz A, Tasbulak O. Relation of red cell distribution width to contrast-induced acute kidney injury in patients undergoing a primary percutaneous coronary intervention. Coron Artery Dis 2015; 26(4): 289-95.

29. Akkoyun DÇ, Akyüz A, Kurt Ö, Bilir B, Alpsoy Ş, Güler N. Relationship between red cell distribution width and contrast-induced nephropathy in patients who underwent primary percutaneous coronary intervention. Turk Kardiyol Dern Ars 2015; 43(7): 613-20.

30. Zhao K, Li Y, Gao Q. Role of red blood cell distribution width in predicting contrast induced nephropathy in patients with stable angina pectoris undergoing percutaneous coronary intervention. Int J Cardiol 2015; 197: 276-8.

31. Evans TC, Jehle D. The red blood cell distribution width. J Emerg Med 1991; 9 Suppl 1: 71-4.

32. Stolker JM, McCullough PA, Rao S, Inzucchi SE, Spertus JA, Maddox TM, Masoudi FA, Xiao L, Kosiborod M. Pre-procedural glucose levels and the risk for contrast-induced acute kidney injury in patients undergoing coronary angiography. J Am Coll Cardiol 2010; 55(14): 1433-40.

33. Kadri Z, Danchin N, Vaur L, Cottin Y, Guéret P, Zeller M, Lablanche JM, Blanchard D, Hanania G, Genès N, Cambou JP. Major impact of admission glycaemia on 30 day and one year mortality in non-diabetic patients admitted for myocardial infarction: results from the nationwide French USIC 2000 study. Heart 2006; 92(7): 910-5.

34. Patti G, Ricottini E, Nusca A, Colonna G, Pasceri V, D'Ambrosio A, Montinaro A, Di Sciascio G. Short-term, high-dose Atorvastatin pretreatment to prevent contrast-induced nephropathy in patients with acute coronary syndromes undergoing percutaneous coronary intervention (from the ARMYDA-CIN [atorvastatin for reduction of myocardial damage during angioplasty--contrast-induced nephropathy] trial. Am J Cardiol 2011; 108(1): 1-7.

35. Leoncini M, Toso A, Maioli M, Tropeano F, Villani S, Bellandi F. Early high-dose rosuvastatin for contrast-induced nephropathy prevention in acute coronary syndrome: Results from the PRATO-ACS Study (Protective Effect of Rosuvastatin and Antiplatelet Therapy On contrast-induced acute kidney injury and myocardial damage in patients with Acute Coronary Syndrome). J Am Coll Cardiol 2014; 63(1): 71-9.

36. Weiss G, Goodnough LT. Anemia of chronic disease. N Engl J Med 2005; 352(10): 1011-23.

37. Valko M, Izakovic M, Mazur M, Rhodes CJ, Telser J. Role of oxygen radicals in DNA damage and cancer incidence. Mol Cell Biochem 2004; 266(1-2): 37-56.

38. Bakris GL, Lass N, Gaber AO, Jones JD, Burnett JC. Radiocontrast medium-induced declines in renal function: a role for oxygen free radicals. Am J Physiol 1990; 258(1 Pt 2): F115-20.

39. Katholi RE, Woods WT, Taylor GJ, Deitrick CL, Womack KA, Katholi CR, McCann WP. Oxygen free radicals and contrast nephropathy. Am J Kidney Dis 1998; 32(1): 64-71. 